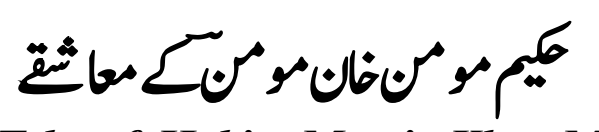

\title{
Love Tales of Hakim Momin Khan Momin
}

Muhammad Tahir Bostan

Lecturer Urdu, Cadat College Sawat, Swat.

\section{KEYWOR D S}

Elated

Failure

Materialistic

True Love

Modesty

Slight

Romance

Depicts

Utter Beloved

\section{A T E S}

\section{A B S T R A C T}

This paper aims a comprehensive investigation to identify the various (love stories) of Hakim Momin Khan Momin. Hakim was a romantic poet. His poetry depicts ideal romance. Hakim Momin Khan Momin was a very much elated person. He faced utter faliar in the art of love. He was fond of Platonic love but he always faced materialistic love from his beloved. He was fed off from the un successful love from his beloved. For romance and true love, he left his educational career incomplete. Hakimi is fond of physical beauty. His poetry mostly consists of modesty and a slight touch of satiation.

DOI: https://doi.org/10.54064/negotiations.v1i3.26

\footnotetext{
Received 30-08-2021

Accepted 02-12-2021

Published 21-12-2021
}

Q R C O D E

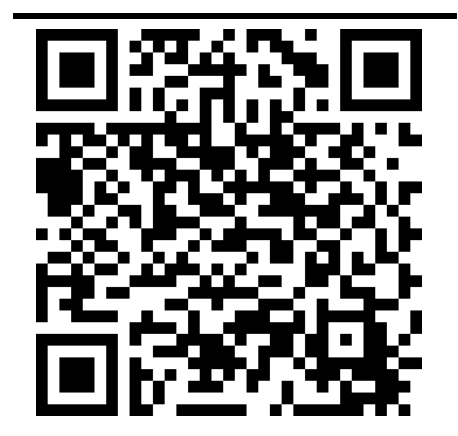

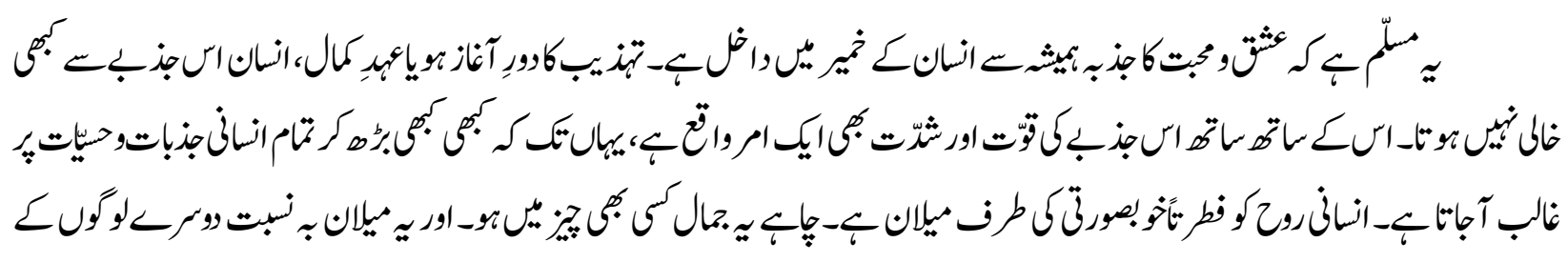




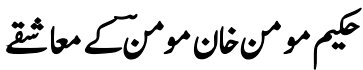

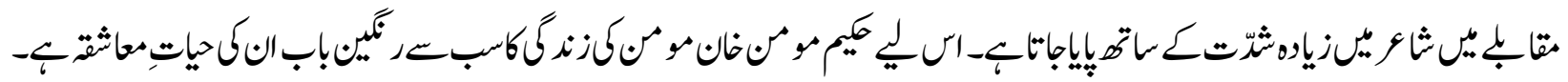

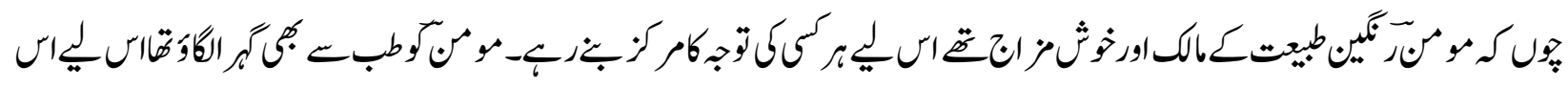

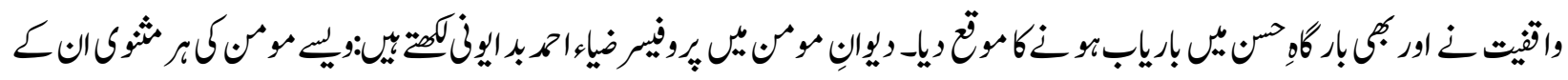

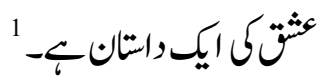

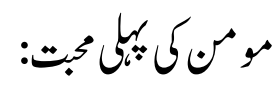

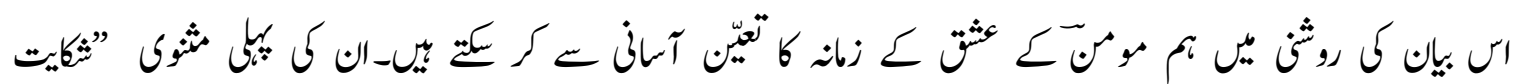

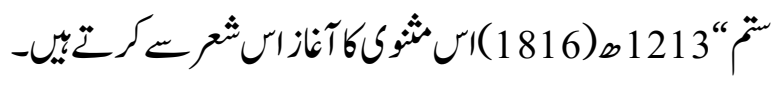

$$
\begin{aligned}
& \text { ائنالث }
\end{aligned}
$$

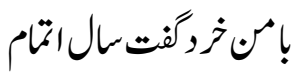

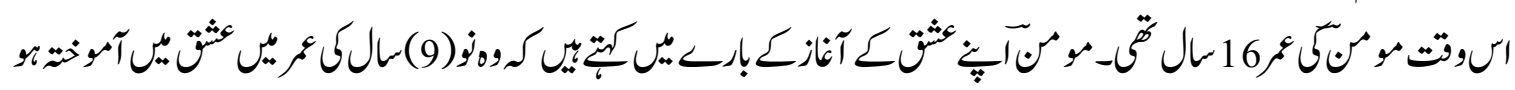

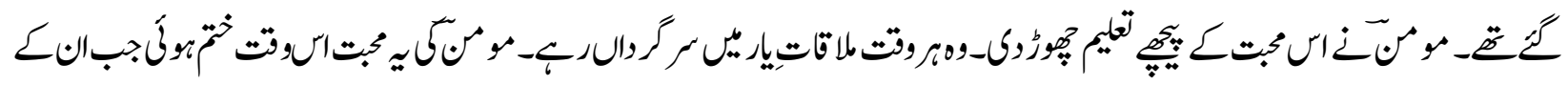

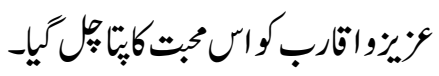

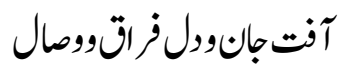

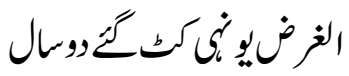

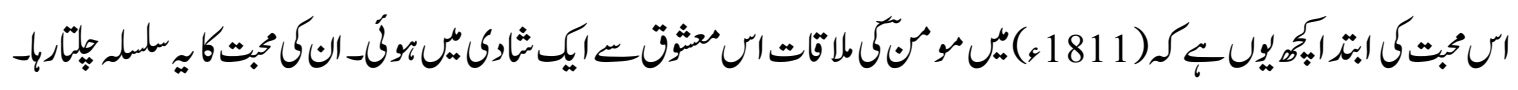

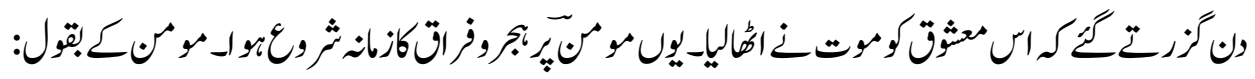

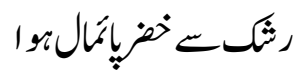

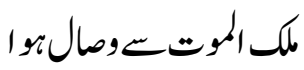

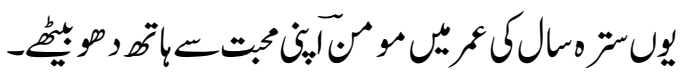

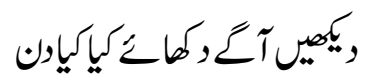

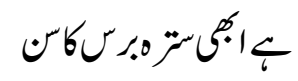

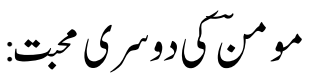

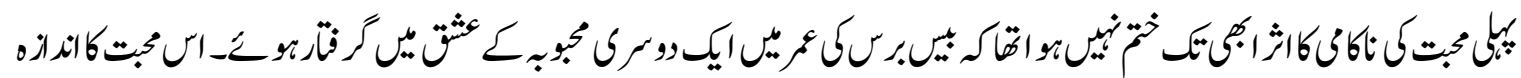

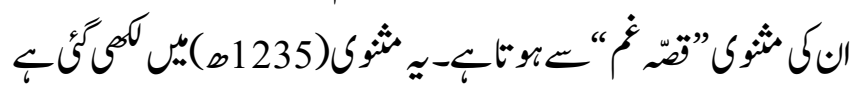

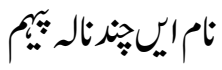

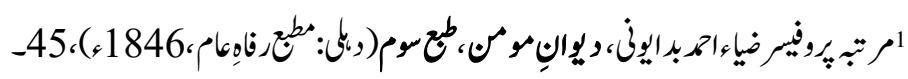




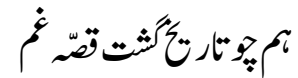

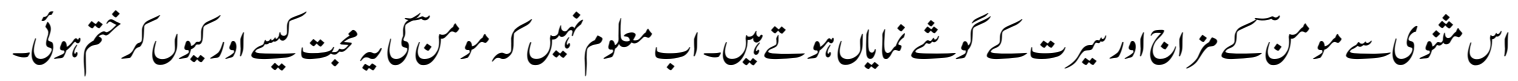

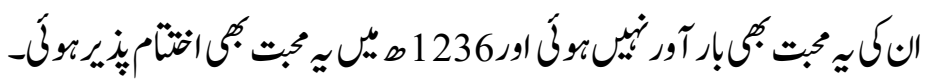

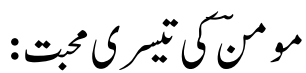

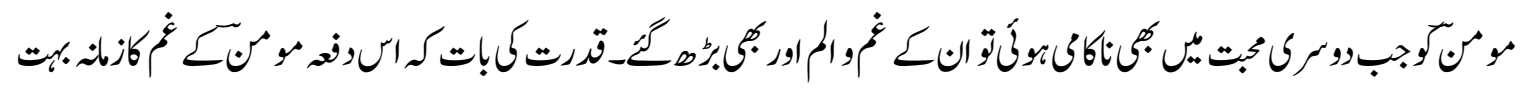

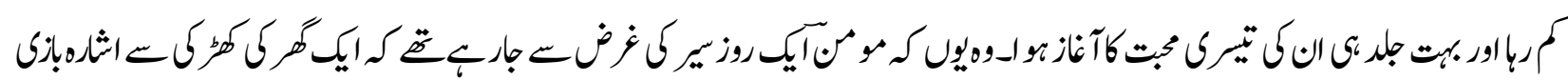

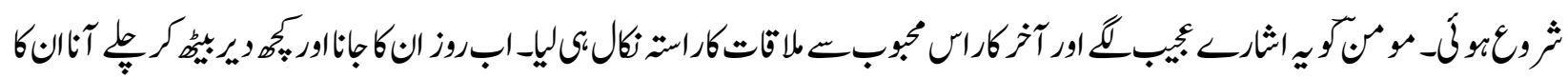

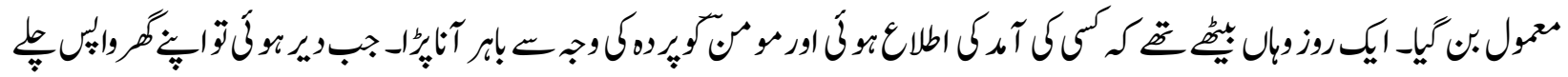

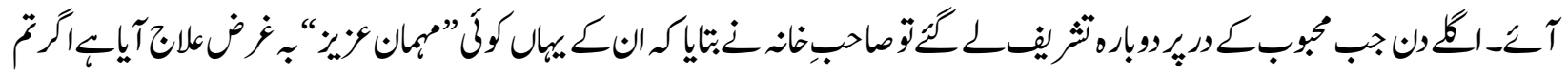

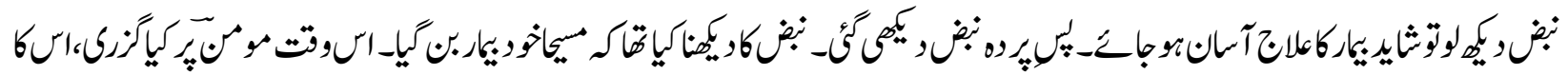

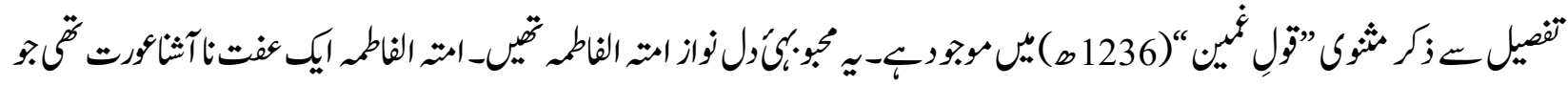

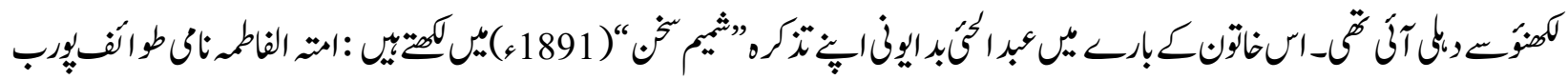

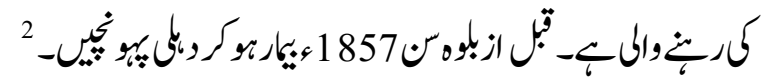

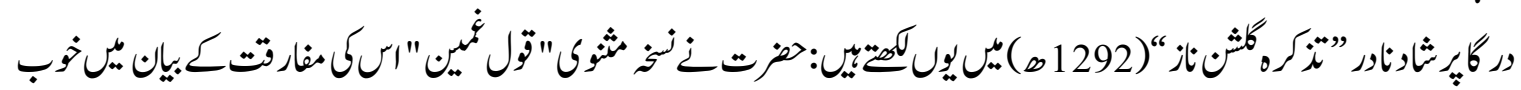

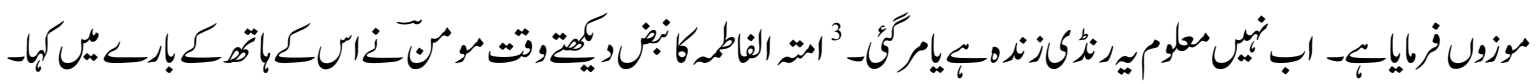
صافتصنل

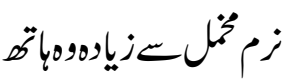

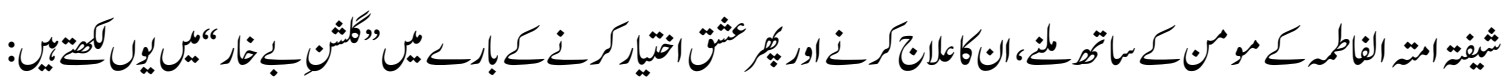

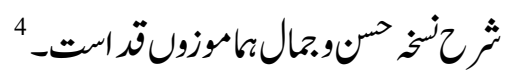

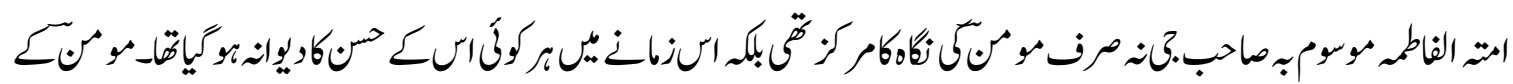

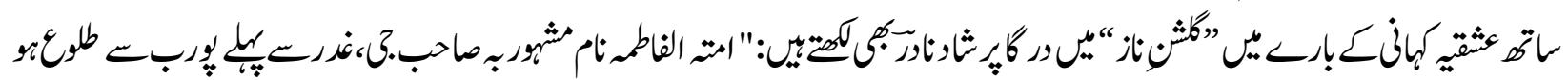

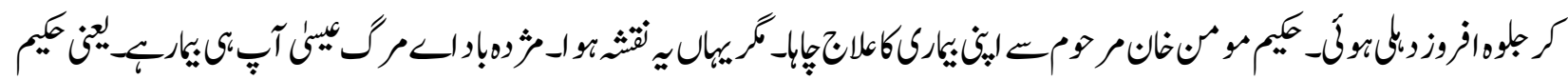

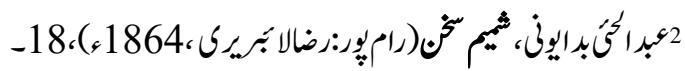

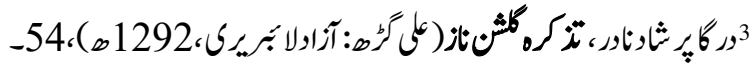

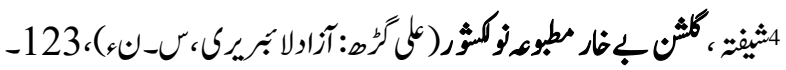




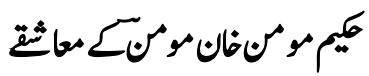

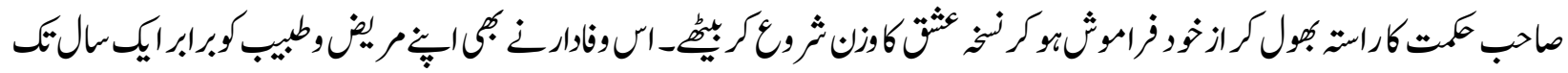

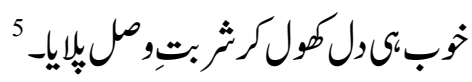

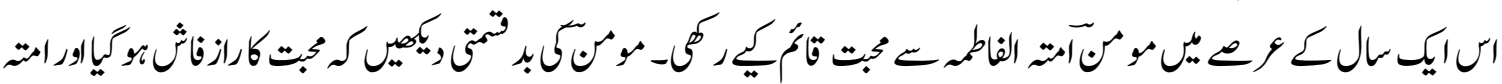

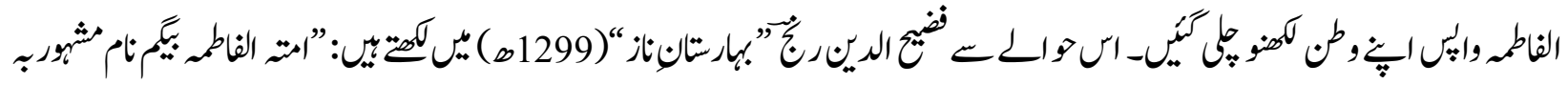

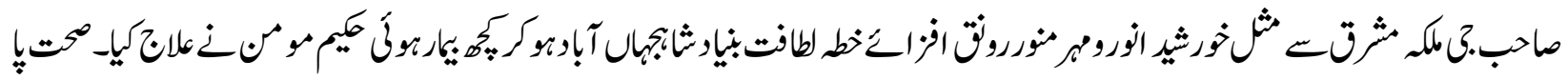

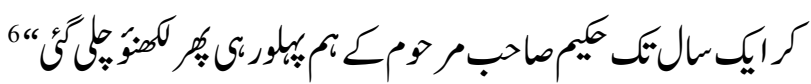

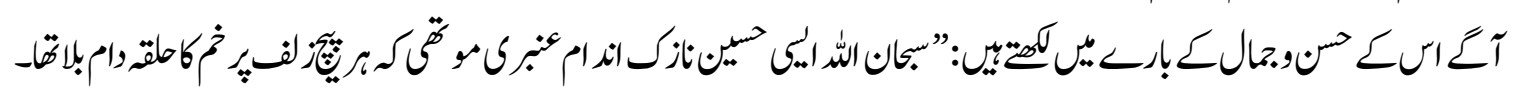

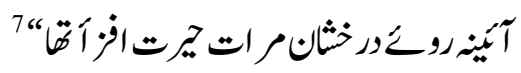

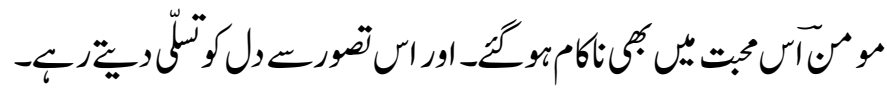

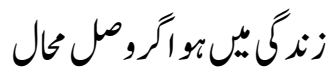

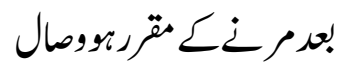

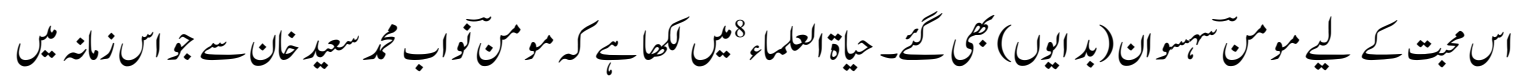

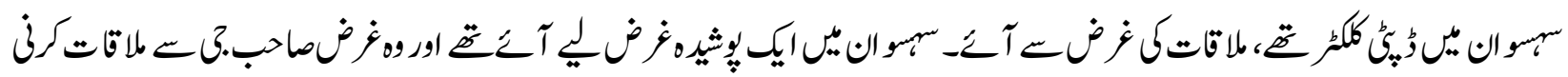

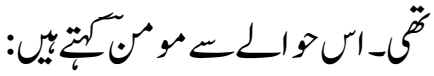

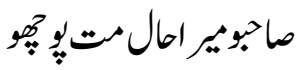

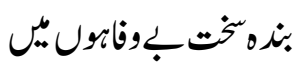

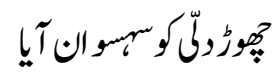

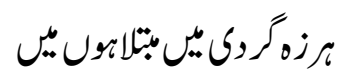

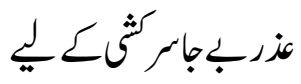

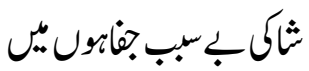

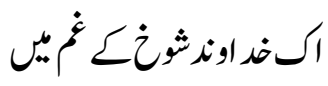

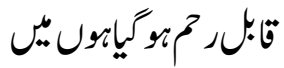

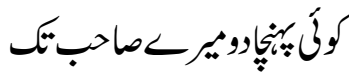

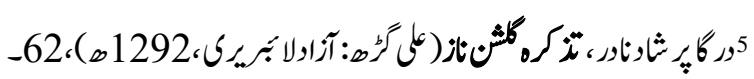

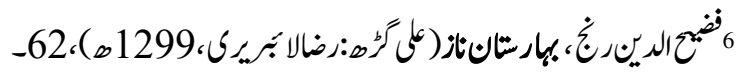




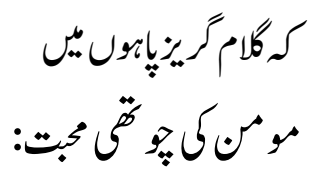

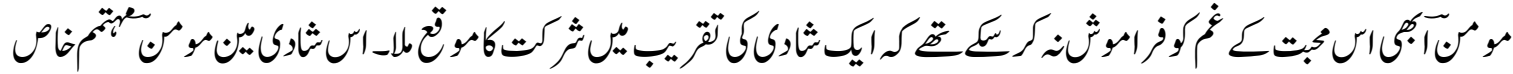

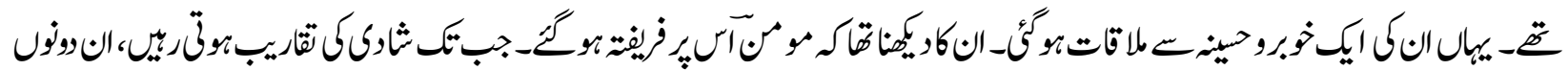

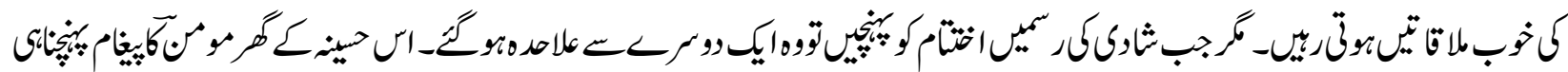

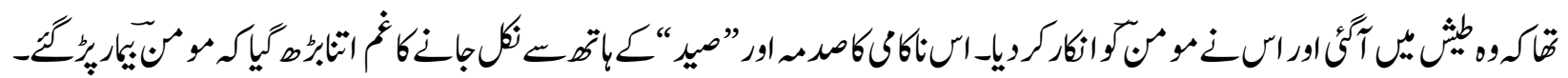

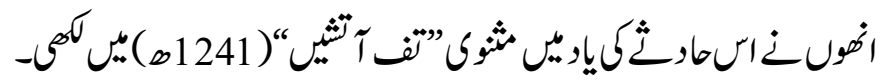

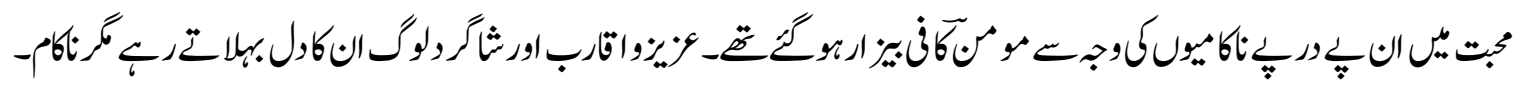

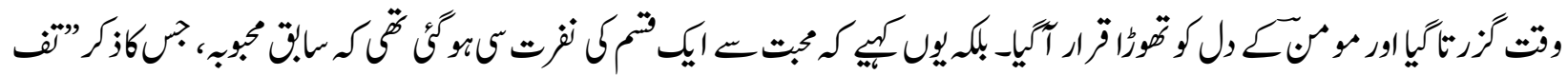

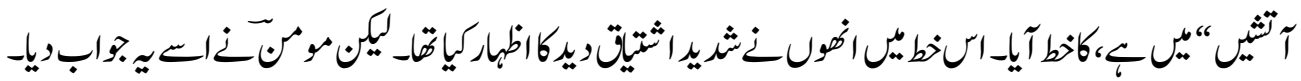

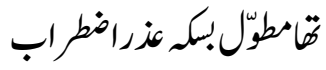

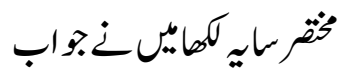

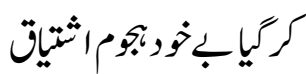

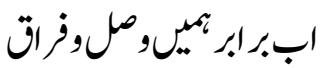

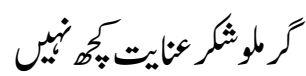

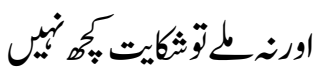

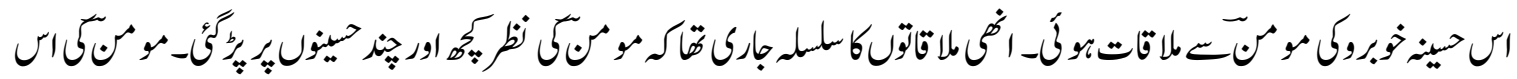

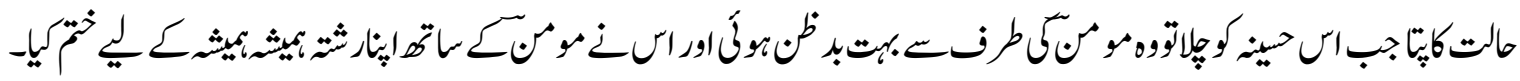

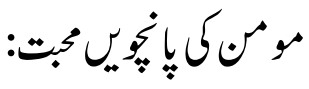

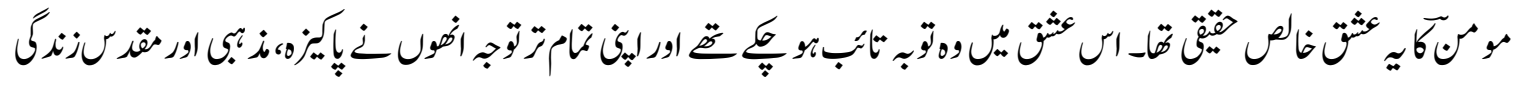

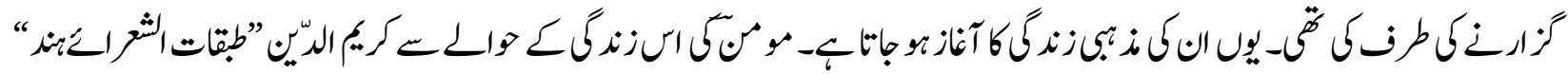

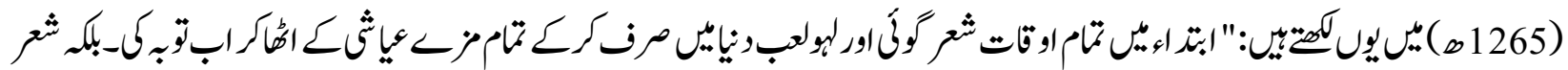

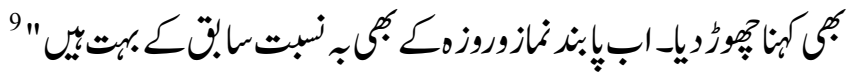




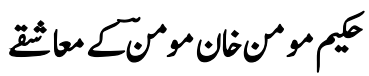

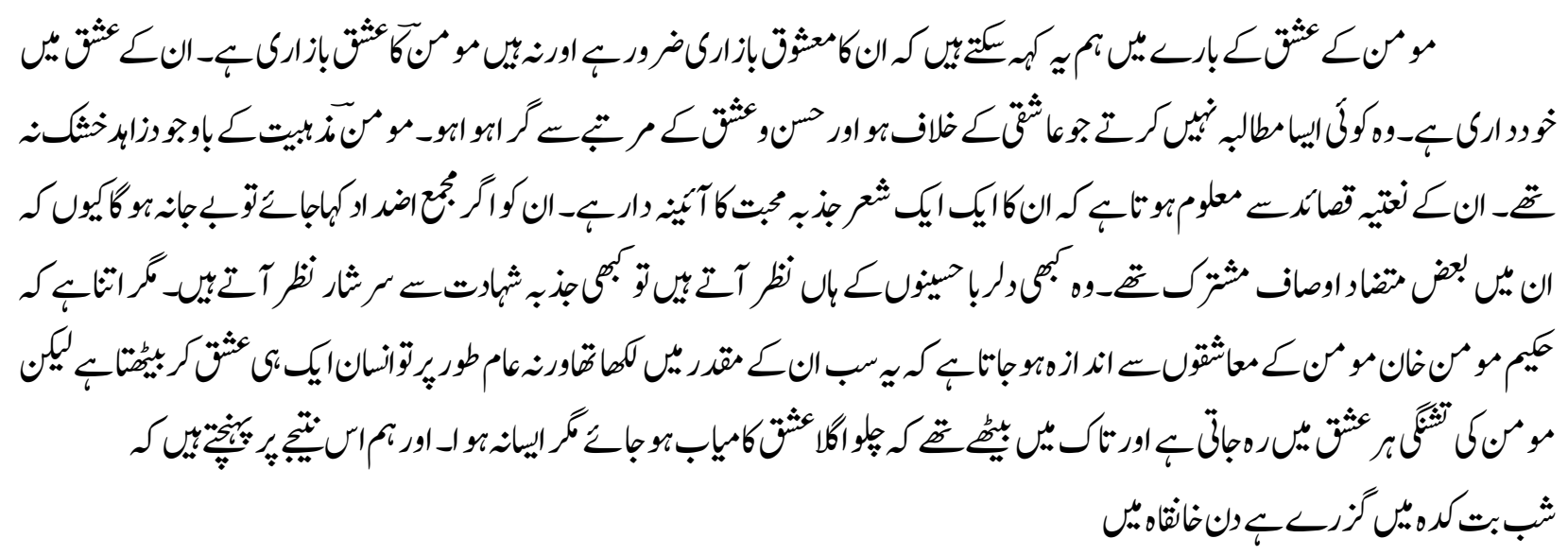

论证行 